\title{
The Effect of Manual Physical Therapy on Improvement in the Range of Motion of Frozen Shoulder Patients: A Meta-Analysis of Cases in South Korea
}

\author{
Chan Myeong Kim¹, Jong Kyung Lee², Jong Ha Hwang'2, Jae Kwang Lee \\ ${ }^{1}$ Korea Safety Health Environment Foundation, Work Environment Health Center, Cheongju, Republic of Korea; ${ }^{2}$ Department of Physical Therapy, \\ Graduate School, Daegu Catholic University, Daegu, Republic of Korea; ${ }^{3}$ Denudeun Hospital, Daegu, Repulic of Korea
}

Purpose: The main purpose of this meta-analysis was to identify the degree of effect size and variables for the impact of manual physical therapy on the improvement in the range of motion of frozen shoulder patients.

Methods: This study collected 8 studies published between 1st January 2010 and 31st December 2020. The analysis of the results verified 49 effect size data and the random effect model was chosen.

Results: First, the full case showed the largest mean effect size of $2.485(p<0.001)$. Second, the size of the effect based on manual therapy and modality therapy showed an effect size of $4.178(p<0.001)$. Third, the outcome group included 6 variables. The external rotation (2.818) variable group showed the largest mean effect size, followed by internal rotation (2.748), flexion (2.643), abduction (2.356), and adduction (2.356). Six outcomes were significant and the mean effect sizes of all the varied groups were above large size. The number of participants showed a 20 or less effect size of 2.478 ( $p>0.737$ ). The number of intervention periods showed 4 weeks 20 or more effect size of 2.782 ( $p>0.294)$. Finally, the 'Trim and Fill' result confirmed that the calibration effect size was $1.471(p<0.001)$.

Conclusion: This study verified that manual physical therapy had a substantial effect on the improvement of the range of motion of patients with frozen shoulders and that the effects were dependent on the methods of outcomes.

Keywords: Frozen shoulder, Manual therapy, Meta-analysis, Range of motion, Shoulder Adhesive Capsulitis

\section{서 론}

현대인들은 신체활동의 감소나 과사용으로 인해 근골격계 질환이 많이 발생하며, 허리통증 다음으로 어깨관절 통증을 자주 접하게 된 다. ' 인체에서 어깨관절은 가장 불안정하며 움직임이 많고 큰 관절이 며, 주변 조직들의 협동적 조절에 의존하여 관절표면 움직임이 일어 나기 때문에 가동범위가 클수록자유롭게 손을 사용할 수 있지만 이 로 인해 여러 가지 질환 발생의 위험이 높은 것으로 알려져 있다.2.3어 깨관절 질환에서 굳은어깨(frozen shoulder) 또는 유착성 관절낭염 (adhesive capsulitis)은 가장 흔하게 접하게 되는 어깨의 질환으로 주요 증상은 관절가동범위를 크게 제한하고 점진적인 통증이 발생하는 원인이 불확실한 질환이다. ${ }^{4}$

일반적으로 굳은어깨는 어깨관절의 벌림과 안쪽돌림, 가쪽돌림의 움직임 감소가 나타나고, 진단기준으로 수동적인 벌림이 $100^{\circ}$ 이하,

Received Sep 15, 2021 Revised Oct 9, 2021

Accepted Oct 25, 2021

Corresponding author Jae Kwang Lee

E-mail dgkora@naver.com
굽힘 $140^{\circ}$ 이하로 정의된다. ${ }^{5}$ 또한 결빙기, 동결기, 해빙기라는 3 단계 주기(cycle)에서 18-24개월 지속되며, 1단계는 결빙기로 심한 통증과 염증으로 인해 어깨관절의 통증과 관절낭 패턴이 발생되어 가동성 제한을 가쪽돌림>벌림>굽힘>안쪽돌림에서 보이는 단계이며, 2단 계는 동결기로 통증이 점차 감소하나 관절의 움직임과 기능에서 제 한이 증가되는 단계이며, 3 단계 해빙기는 점진적으로 어깨관절 움직 임이 회복되고 불편함이 감소되는 단계라 하였다. ${ }^{6}$ 이러한 굳은어깨 는 전체 인구의 2-5\%에 유병률이 있는 것으로 추정되고 있으며, 40-60 세 남자보다는 주로 여성에서 더 많이 발병되며, 6-17\%는 회복 후 다 른 쪽 어깨관절에서 5 년 안에 재발하는 것으로 보고되고 있다.

발병원인은 아직 정확히 밝혀지지는 않았지만, Goldman 등은 원 인으로 어깨관절과 주위조직의 비정상적인 상태의 기간이 길어질수 록 유발의 원인이 된다고 하였고, Salter는 노화에 따라 관절낭의 혈 액공급이 불충분해지고 이로 인해 간질 조직에 영양공급이 감소되
Copylight (C)2021 The Korean Society of Physical Therapy

This is an Open Access article distribute under the terms of the Creative Commons Attribution Non-commercial License (https:// creativecommons.org/license/by-nc/4.0.) which permits unrestricted non-commercial use, distribution, and reproduction in any medium, provided the original work is properly cited. 
어 변성이 생기며, 변성된 관절낭과 건의 질환은 국소적인 괴사를 나 타내는 병리적인 변화로 인해 괴사된 부위에 석회화가 진행되고 약 해져 약간의 외상, 파열에도 열상이 되기 쉽다고 하였고, 내인성 원인 으로는 가시위근의 힘줄염, 석회화, 어깨돌림근의 부분적인 열상, 위 팔두갈래근 힘줄염과 고정된 기간 등이 속하고 외인성 요인으로는 어깨 부위에 통증이 되는 모든 인자와, 경추추간판 탈출증, 심근경색 과 뇌혈관 손상 등의 질환에 의해서도 나타날 수 있다고 하였다. ${ }^{10}$

굳은어깨가 유발되면 관절면과의 유착이 서서히 증가하고 관절 활액막이 비후되어 통증의 증가와 점진적으로 관절가동범위가 감소 되며, 유연성 소실과 관절의 섬유화를 동반한 만성염증 및 조직의 변 형으로 인하여 일상생활동작에 어려움을 초래하므로 다양하고 적 극적인 중재가 필요하다.1112 만약 치료가 적절히 이루어지지 않게 되 면 환자의 $40 \%$ 가 관절가동범위 제한과 통증이 나타났으며, $11 \%$ 는 어 깨 기능장애가 영구적으로 나타난다는 보고도 있다. ${ }^{13}$ 과거에는 1-2 년 정도 경과되면 치료를 하지 않아도 수 개월, 수 년 동안에 걸쳐서 부분적 또는 완전 회복될 수 있는 질환으로 가볍게 여겨지는 경향이 있었지만, 최근에는 적절한 치료가 적용되지 않으면 어깨관절의 장 애가 지속된다고 알려져 여러 치료방법이 연구되고 적용되고 있다. ${ }^{14}$

이 질환의 치료목표는 어깨관절의 관절가동범위의 향상을 통하 여 운동성을 촉진하고 통증을 감소시켜 정상적인 관절 기능을 회복 시키는 것이며, ${ }^{15}$ 보존적 치료방법으로 일반적으로 전기치료, 스트레 칭, 관절가동술, 도수치료 등이 있다. ${ }^{16}$ 특히 굳은어깨의 주요 증상인 관절가동범위 증진을 위한 치료법으로 코드만(Codman) 운동법은 오랫동안 많이 사용되어온 잘 알려진 치료법이고, 능동, 수동운동과 복합적인 운동을 계획하여 적절한 치료기술과 기구와 기계를 활용 한 접근은 회복의 속도와 치유를 촉진시킬 수 있다. ${ }^{15}$

본 연구에서 선정된 연구들의 치료 기법으로는 도수치료, 도수 스 트레칭, 근에너지기법, 신경가동운동, 스포츠마사지, 연부조직가동 술, 경혈지압법이 있다. 도수치료는 신체의 기능장애가 있는 질환들 에 해부학적 및 운동역학적 지식을 가진 치료사가 손을 이용하여 통 증이 없는 최대한의 가동범위와 자세의 균형을 확보하여 신체기능 향상을 유도하는 치료법이다. ${ }^{17}$

도수 스트레칭은 적절한 스트레칭을 시행할 경우 굳은어깨로 인 한 관절가동범위 제한과 통증을 회복할 수 있는 것으로 제시되었으 며, ${ }^{16}$ 근에너지기법은 근육의 리드미컬한 수축을 통해 근육의 혈액 및 림프액 순환을 촉진하고 고유수용성 피드백과 관절운동 조절 및 운동 학습에 영향을 주어 통증을 감소시킨다.18

신경가동술은 축삭 수송을 향상시켜 신경 전도를 촉진시키고, 압 박이 감소되어 신경으로의 혈액 순환을 증가시켜 연부조직의 회복 을 촉진시킨다고 하였다. ${ }^{19}$ 스포츠 마사지는 순환증진과 유연성 증가, 신경근 흥분억제를 시키고 근의 협응성을 증가시키며, ${ }^{20}$ 연부조직 가
동술은 제한되거나 유착된 조직을 깨트려주어 혈류를 증진시켜 통 증을 조절하고 가동성을 증진시키는 기법이다. ${ }^{21}$ 경혈지압 또한 혈류 증진을 통해 요통, 만성 두통 및 외상성 통증과 같은 다양한 통증을 감소시키는 것으로 나타났다.22 각치료법들 간에는 이론적 배경과 기 술적 차이는 존재하지만 여러 기법들을 활용하여 임상현장에서 사 용될 뿐만 아니라 관련된 연구가 많이 진행되고 있다.

본 연구에서는 최근 10 년간 한국에서 진행된 굳은어깨 연구들을 수집하여 도수치료가 어깨의 관절가동범위의 개선에 어떠한 영향을 미치는지 알아보고 최근까지의 굳은어깨 연구들에 대한 종합적인 분석과 객관적인 효과크기를 제시하는 결론을 도출하고자 한다.

\section{연구 방법}

\section{1. 연구 설계}

본 연구의 대상은 굳은어깨를 호소하는 대상자들이고 중재방법은 도수치료가 적용된 중재이며, 비교집단은 단일 사례들이다. 연구 결 과는 어깨의 관절가동범위이며, 연구 설계 유형은 무작위 대조실험 으로 단일집단 사전-사후 실험 연구로 선정하였다.

\section{2. 자료 선정}

문헌 선정의 구체적인 선정기준은 다음과 같다. 1) 굳은어깨 진단을 받은 대상으로 한 연구, 2) 물리치료 중재 방법이 제시된 연구, 3) 통계 적 수치가 제시된 연구, 4) 사전-사후 무작위 대조시험 설계방식의 실 험연구, 5) 2010년 1월 1일-2020년 12월 31일 까지의 연구.

문헌 배제기준은 다음과 같다. 1) 주사, 침, 진단, 약물, 수술을 적용 한 연구, 2) 사전-사후 무작위 대조시험 설계방식이 아닌 연구, 3) 통계 적 수치가 없는 연구, 4) 'Full text'를 얻을 수 없는 연구.

자료수집의 전 정은 PRISMA 흐름도에 따라 수행하였고, ${ }^{23}$ 주제어 로 국내연구에서 많이 사용되는 'Frozen shoulder', 'Adhesive capsulitis' 를 검색하여 학술연구정보(RISS), 한국학술정보(KCI)에서 총 213건 의 문헌이 검색되었다. 자료선정과 검토 및 연구과정은 연구자들과 선정기준과 제외기준에 대한 협의를 거쳐 기준을 정해 상세히 검토 하여 최종 선정하였다(Figure 1).

\section{3. 연구의 비뚤림 위험 평가 및 데이터 코딩}

8편의 연구가 최종선정 되었으며, Cochrane Library의 Risk of bias평가 도구와 Review manager 5.4 프로그램을 이용하여 연구들의 비뚤림 위 험 평가를 진행하였다. 데이터의 코딩은 단일집단(사전-사후검사) 메 타분석 방법을 사용하여 평균과 표준편차 값을 가진 연구만을 활용 하여 연구자명, 중재 방법, 평가 방법, 대상자 수, 치료기간, 논문명으 로 코딩하여 $\operatorname{csv}$ 파일 형태로 변환하여 분석에 사용하였다. ${ }^{24}$ 


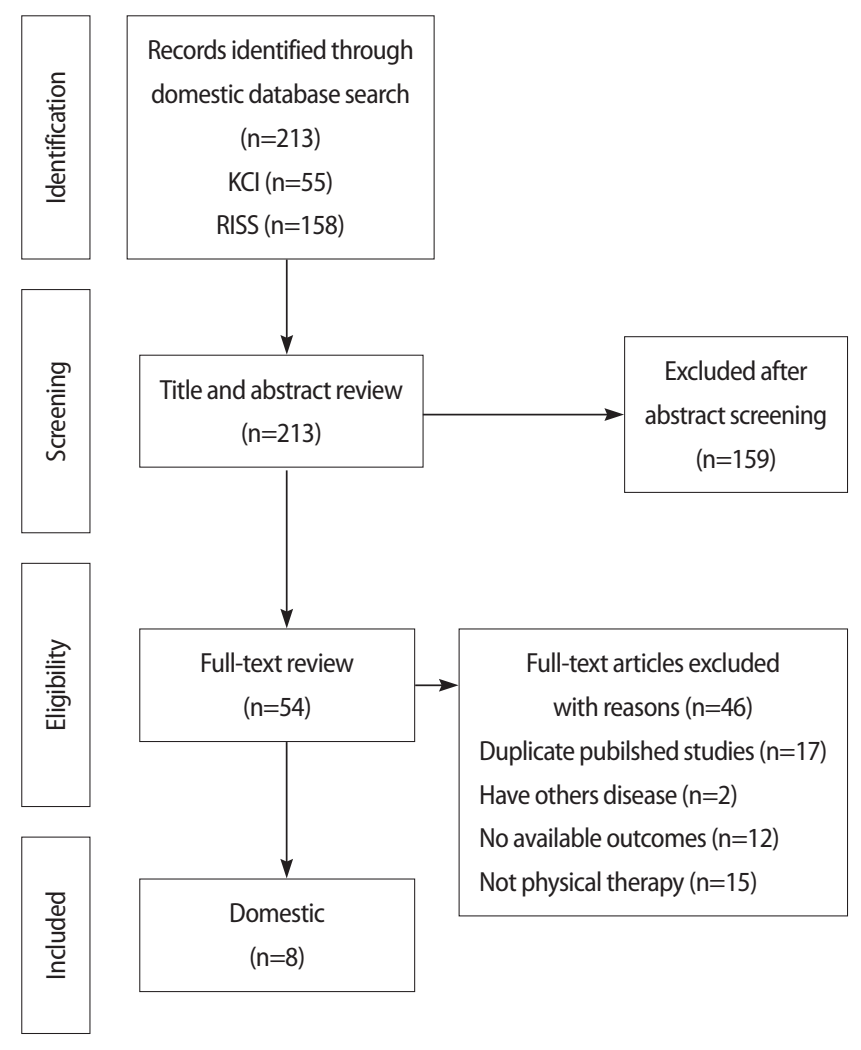

Figure 1. The picture of PRISMA flow chart.

\section{4. 자료 분석과 해석}

1) 통계 처리

$\mathrm{R}$ 프로그램 패키지의 'meta', 'metafor'를 이용하였고, 수집된 개별 연구 들의 이질성이 크기 때문에 분석에서 무선효과모형을 적용하여 효 과크기를 산출하였다. ${ }^{24}$ 효과크기는 표준화된 평균차이로 해석하며, 교정된 효과크기 $(\mathrm{g})$ 를 해석하는 방식은 Cohen's의 d해석과 같다. ${ }^{23,24}$

(1) Small effect size: $\mathrm{ES}_{\mathrm{sm}} \leq 0.20$

(2) medium effect size: $0.20<\mathrm{ES}_{\mathrm{sm}}<0.80$

(3) Large effect size: $\mathrm{ES}_{\mathrm{sm}} \geq 0.80$

\section{2) 이질성 검증}

연구들의 효과크기 동일성을 검증할 때 $\mathrm{Q}$ 와 $\mathrm{df}$ 값이 사용되며, 이질 성의 비율은 $\mathrm{I}^{2}$ 으로 나타내고 $\mathrm{I}^{2}$ 은 전체 분산에 대한 실제 연구 간 분 산의 비율을 나타내며, 각각의 연구에서 산출된 효과크기들의 이질 성 정도를 나타낸다. ${ }^{25}$

\section{결 과}

본 연구의 전체 효과크기는(ES=2.48) 큰 효과크기로 통계적으로 유 의하며 $(\mathrm{p}<0.05), \mathrm{I}^{2}$ 값이 $87 \%$ 로 나타났다. $\mathrm{I}^{2}$ 은 총 분산에 대한 연구 간
분산의 비율을 나타내고, 일반적으로 $\mathrm{I}^{2}$ 이 $25 \%$ 이면 작은 정도의 이질 성으로, $50 \%$ 이면 중간정도의 이질성으로, $75 \%$ 이상이면 이질성이 매 우 큰 것으로 해석한다. ${ }^{25}$ 따라서 본연구의 전체 사례에 대한 $I^{2}$ 이 $75 \%$ 이상이므로 이질성은 크다고 할 수 있다(Figure 2). 중재유형에 따른 분석 결과 Modality+Manual 중재가(ES=4.54) 높게 나타났으며, 95\% 신뢰구간에서 통계적으로 유의하게 나타났다. 각 중재별 효과크기는 다음과 같다(Figure 2).

평가방법에 따른 효과크기에서 사례 수는 $\mathrm{ER}(\mathrm{k}=11), \mathrm{FL}(\mathrm{k}=11), \mathrm{IR}$ $(\mathrm{k}=11), \mathrm{AB}(\mathrm{k}=8), \mathrm{EX}(\mathrm{k}=6), \mathrm{AD}(\mathrm{k}=2)$ 의 순서이며, 효과크기는 $\mathrm{ER}$ ( $\mathrm{ES}=2.82), \mathrm{IR}(\mathrm{ES}=2.75), \mathrm{FL}(\mathrm{ES}=2.64), \mathrm{AB}$ ( $\mathrm{ES}=2.36), \mathrm{EX}(\mathrm{ES}=2.32)$, $\mathrm{AD}(\mathrm{ES}=0.82)$ 의 순으로, Cohen23의 기준에 의하면 모두 큰 효과 크 기로 나타났다(Table 1).

대상자 수에 따른 사례 수는 20명 이하 $(\mathrm{k}=42), 20$ 명 초과 $(\mathrm{k}=7)$ 이 며, 효과크기는 20 명 초과 $(\mathrm{ES}=2.63), 20$ 명 이하 $(\mathrm{ES}=2.48)$ 로 높게 나타 났고, $95 \%$ 신뢰구간에서 통계적으로 유의하게 나타났다. 중재기간에 따른 사례 수는 4 주 이하 $(\mathrm{k}=27), 4$ 주 초과 $(\mathrm{k}=22)$ 이며, 효과크기는 4 주 초과 $(\mathrm{ES}=2.78), 4$ 주 이하( $\mathrm{ES}=2.32)$ 로 높게 나타났고, $95 \%$ 신뢰구간 에서 통계적으로 유의하게 나타났다(Table 1).

본 연구의 신뢰도를 높이기 위해 'Trim and Fill'을 이용하여, ${ }^{26}$ 비대 칭을 대칭으로 교정하여 출간오류를 확인한 결과 19 개의 사례가 추 가되어 68 개의 사례로 보정된 효과크기는 $\mathrm{ES}=1.47$ 이며, $95 \%$ 신뢰구 간과 Q값이 $637.53(\mathrm{df}=67, \mathrm{p}<0.05)$ 로 통계적으로 유의한 것으로 나타 났다 $(\mathrm{p}<0.05)$ (Table 2, Figure 3).

\section{고 찰}

본 연구는 어깨의 주요 질환인 굳은어깨에 도수치료를 적용한 국내 연구들을 대상으로 메타분석을 통하여 도수치료가 관절가동범위의 개선에 미치는 효과에 대한 종합적인 결과를 도출하기 위해 진행되 었다. 연구결과 전체사례에 대한 효과크기는 $(\mathrm{ES}=2.48)$ 이고, 중재유 형에서 모달리티 치료와 도수치료를 함께 적용한 경우가 더 높은 효 과크기를 보였으며, 개별 중재에서도 모달리티와 마사지를 적용한 사 례가 가장 높은 효과크기를 보였다(Figure 2). 이러한 결과는 어깨에 도수치료를 적용한 21 개의 해외 메타분석 연구 결과에서도 도수치료 는 통증감소와 관절가동범위의 개선에 효과적이며, 모달리티나 운 동프로그램에 추가적으로 도수치료를 적용할 경우 그 효과는 더 높 아진다는 결과와 일치한다. ${ }^{27}$

한국의 임상 현장에서도 모달리티와 도수치료가 함께 많이 시행 되고 있으며, $\mathrm{Ma}$ 등 28 의 연구에서 도수치료와 모달리티 치료를 주 3 회, 4 주간 실시한 결과 관절가동범위와 통증과 기능적 평가에서 모 두 유의한 치료결과를 보고하였다. 본 연구 결과로 관절가동범위의 


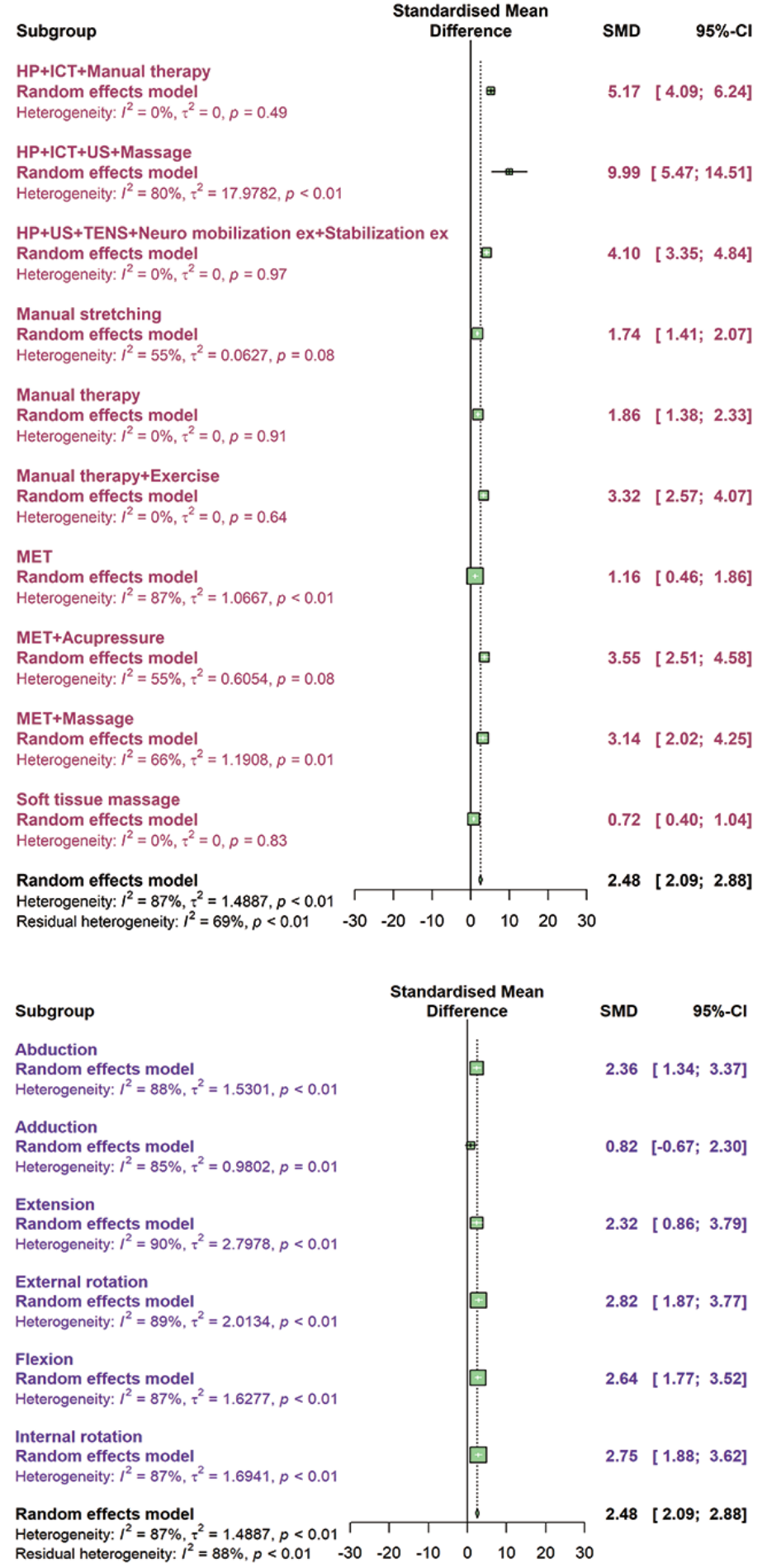

Figure 2. The picture of forest plot according to intervention and outcome.

개선에 미치는 효과크기를 확인해 본 결과 어깨관절에서 나타나는 가동범위 모두 큰 효과 크기로 개선됨을 확인할수 있었다. 특히 어깨 관절의 가쪽돌림, 안쪽돌림, 굽힘, 벌림, 폄의 효과크기가 매우 높은 것으로 나타났다. Camarinos 등 29 의 메타분석 연구에 따르면 어깨에 도수치료를 적용한 연구들의 결과에서 통증감소와 관절가동범위 뿐
만 아니라 삶의 질의 개선에도 유의한 효과를 보고하였다.

굳은어깨의 치료에서 관절가동범위의 회복은 가장 중요한 핵심이 며, 초기에 겨드랑이 부위와 관절낭의 유착과 조직의 길이 변화를 방 지하는 것이 매우 중요하다. ${ }^{30}$ 도수치료의 관절가동운동은 관절 내 움직임과 정상적인 구름과 활주를 회복시켜 정상적이고 통증이 없 


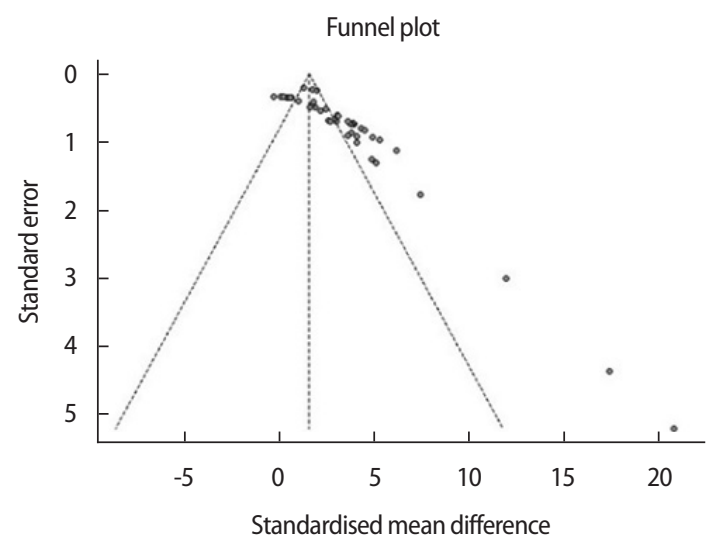

Figure 3. The picture of Funnel plot and Trim and Fill.

Table 1. Effect size according to the outcomes

\begin{tabular}{lcccccc}
\hline \multirow{2}{*}{ Outcomes } & \multirow{2}{*}{$k$} & $\mathrm{ES}(\mathrm{g})$ & \multicolumn{2}{c}{$95 \% \mathrm{Cl}$} & \multirow{2}{*}{$\mathrm{Q}(\mathrm{df})$} & $\mathrm{p}$ \\
\cline { 4 - 5 } & & & $\mathrm{LL}$ & $\mathrm{UL}$ & & \\
\hline $\mathrm{AB}$ & 8 & 2.36 & 1.34 & 3.37 & $5.88(5)$ & $>0.318$ \\
$\mathrm{AD}$ & 2 & 0.82 & -0.67 & 2.30 & & \\
EX & 6 & 2.32 & 0.86 & 3.79 & & \\
ER & 11 & 2.82 & 1.87 & 3.77 & & \\
FL & 11 & 2.64 & 1.77 & 3.52 & & \\
IR & 11 & 2.75 & 1.88 & 3.62 & & \\
\hline
\end{tabular}

ES: Effect size, 95\%, k: Number of effect size, Cl: 95\% Confidence interval, I2: Between-study variability, LL: Lower limit, UL: Upper limit, AB: Abduction, AD: Adduction, EX: Extention, ER: External rotation, FL: Flexion, IR: Internal rotation.

는 관절을 만드는 것이 목적이다. ${ }^{31}$ 이러한 치료적 접근으로 Kaltenborn의 오목-볼록 규칙과 능동관절운동을 병행한 치료방법을 적용 하게 되면 가동범위의 증가와 통증감소에 매우 효과적이다. ${ }^{32}$ Yoon 등 ${ }^{33}$ 은 어깨관절에 Mulligan 치료법과 전기치료의 효과를 비교한 연 구에서 통증의 감소는 전기치료가 더 효과적이지만 관절가동범위의 증가에는 Mulligan 치료법이 효과적임을 입증하였다.

도수치료는 통증이 나타나는 지점에 적용하였을 때, 통증의 즉각 적인 감소와 기능향상이 나타났으며, ${ }^{34}$ 이러한 결과는 중추신경계의 하행통증 조절체계를 자극하여 진통효과를 일으킨 결과이다..$^{35}$ 또한 도수치료를 통해 관절수용기를 자극하게 되면 빠른 전달을 하는 큰 직경의 고유수용성 신경섬유가 자극되어 느린 전달을 하는 작은 직 경의 통증전달 신경을 차단시켜 통증정보는 최소화되고, 통증의 감 소로 인해 근육이완이 되는 이차적 효과가 나타나게 된다. ${ }^{36}$

본 연구의 조절변인 결과에서는 치료 대상자수에 대한 사례 수는 20 명 이하가 많게 나타났으며, 효과크기는 20 명 초과일 때 더 높은 것 으로 보아 추후 연구에서는 보다 많은 대상자수로 연구가 진행될 필 요가 있다. 중재기간의 경우 4 주 이하의 치료가 많이 이루어 졌음을 알 수 있고, 효과크기는 4 주 초과의 기간에서 높게 나타났다. Peek ${ }^{37}$ 의 메타분석 연구에서는 26-52주간의 치료에서 어깨의 통증과 장애지

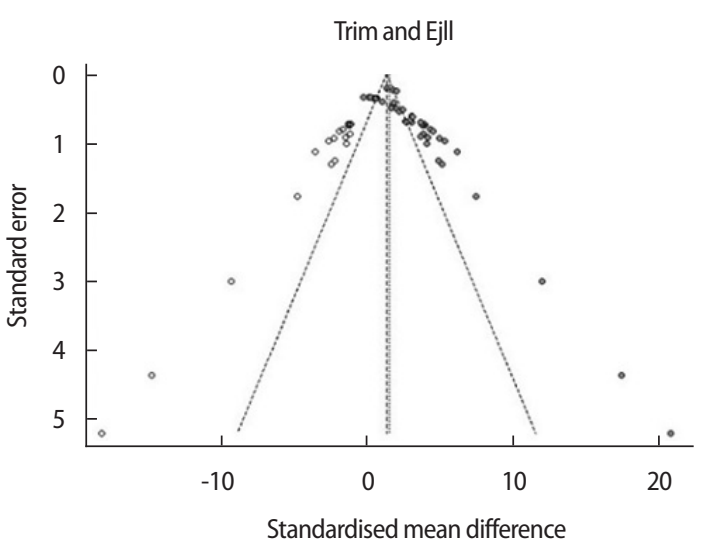

Table 2. Trim and Fill results

\begin{tabular}{lccccccc}
\hline $\begin{array}{l}\text { Publication } \\
\text { bias }\end{array}$ & \multirow{2}{*}{$\mathrm{k}$} & $\mathrm{ES}(\mathrm{g})$ & \multicolumn{3}{c}{$95 \% \mathrm{Cl}$} & \multirow{2}{*}{$\mathrm{Q}(\mathrm{df})$} & $\mathrm{p}$ \\
\cline { 4 - 5 } & & & $\mathrm{LL}$ & $\mathrm{UL}$ & & \\
\hline Trim and Fill & 68 & 1.47 & 1.05 & 1.89 & $637.53(67)$ & $<0.001$ \\
\hline
\end{tabular}

수의 감소를 나타내고 있는 것을 보아 한국의 연구에서도 보다 많은 대상자수와 중재기간에 대한 연구가 이루어져야 할 것이다.

본 연구의 결과에 대한 신뢰도를 검증하기 위해 비대칭을 대칭으 로(Trim and Fill)교정분석한 결과 19 개의 사례가 추가되어 총 68 개의 사례로 보정된 효과크기는 $\mathrm{ES}=1.47$ 이며, $95 \% \mathrm{CI}$ 신뢰구간이 1.05-1.89 로 출간오류 검증에서도 통계적으로 유의한 결과를 보여 굳은어깨 에 물리치료는 큰 효과가 있다는 것을 확인할 수 있었고, 대상자수, 중재기간의 조절 변인에 의해 영향을 받는 것을 알 수 있었다. 따라서 본 연구 결과는 굳은어깨 환자에게 많이 적용되는 도수치료의 효과 를 종합적인 결과로 제시했으며, 국내연구 현황을 메타분석으로 고 찰해 본 연구이다.

본 연구에서 고려해야 할 한계점으로는 첫째, 물리치료학 분야 전 문가들과 함께 문헌 선정 및 검토하고 출간오류를 최소화하기 위해 (Trim and Fill)을 활용한 보정을 진행했음에도 메타분석이 가진 한계 인 출간오류를 완벽히 해소했다고 할 수는 없을 것이다. 둘째, 서로 다 른 연구들을 모아 종합적인 결과를 도출했지만 메타분석의 한계인 이질성이 높다는 단점을 완전히 보완할 수는 없었다. 이질성은 각 연 구에서 나타난 효과크기의 분포 정도, 연구 간 효과크기가 일관되지 않은 정도를 의미한다. 하지만 메타분석의 목표는 효과크기의 평균 을 도출하는데 있지 않고 이질성이 있는 효과크기의 전체 패턴을 종 합하여 이해하는 것이므로, ${ }^{38}$ 국내 연구들의 연구 현황을 파악하고 굳은어깨에 대한 도수치료의 관절가동범위 개선효과와 효과적인 기 법에 대한 종합적인 결과를 제시한 것에 의미가 있을 것이다. 


\section{REFERENCES}

1. Bjelle A. Epidemiology of shoulder problems. Baillieres Clin Rheumatol. 1989;3(3):437-51.

2. Rawat P, Eapen C, Seema KP. Effect of rotator cuff strengthening as an adjunct to standard care in subjects with adhesive capsulitis: a randomized controlled trial. J Hand Ther. 2017;30(3):235-41.

3. Van der Windt DA, Koes BW, de Jong BA et al. Shoulder disorders in general practice: incidence, patient characteristics, and management. Ann Rheum Dis. 1995;54(12):959-64.

4. Reeves B. The natural history of the frozen shoulder syndrome. Scand J Rheumatol. 1975;4(4):193-6.

5. Buchbinder R, Hoving JL, Green S et al. Short course prednisolone for adhesive capsulitis (frozen shoulder or stiff painful shoulder): a randomised, double blind, placebo controlled trial. Ann Rheum Dis. 2004; 63(11):1460-9.

6. Jain TK, Sharma NK. The effectiveness of physiotherapeutic interventions in treatment of frozen shoulder/adhesive capsulitis: a systematic review. J Back Musculoskelet Rehabil. 2014;27(3):247-73.

7. Asheghan M, Aghda AK, Hashemi E et al. Investigation of the effectiveness of acupuncture in the treatment of frozen shoulder. Mater Sociomed. 2016;28(4):253.

8. Goldman AB, Dines DM, Warren RF. Shoulder arthrography: technique, diagnosis, and clinical correlation. Massachusetts, Little Brown \& Company, 1982;139-48.

9. Salter RB. Textbook of disorders and injuries of the musculoskeletal system: an introduction to orthopaedics, fractures and joint injuries, rheumatology. 2nd ed. Baltimore, Williams and Wilkins, 1983;240-4.

10. Kim SM, Lee HO, Bae SS. Effects on frozen shoulder as seen in the comparison hold-relax technique and ROM exercise. J Kor Phys Ther. 1995;7(1):51-9.

11. Loew M, Heichel TO, Lehner B. Intraarticular lesions in primary frozen shoulder after manipulation under general anesthesia. J Shoulder Elbow Surg. 2005;14(1):16-21.

12. Jeon CB, Choi SJ, Oh HJ et al. The effects of high intensity laser therapy on pain and function of patients with frozen shoulder. J Kor Phys Ther. 2017;29(4):207-10.

13. Hand GCR, Athanasou NA, Matthews T et al. The pathology of frozen shoulder. J Bone Joint Surg Br. 2007;89(7):928-32.

14. Levy O, Rath E, Atar D. Combined treatment for adhesive capsulitis of the shoulder. Harefuah. 1997;133(9):357-9.

15. Jerosch J, Nasef NM, Peters O et al. Mid-term results following arthroscopic capsular release in patients with primary and secondary adhesive shoulder capsulitis. Knee Surg Sports Traumatol Arthrosc. 2013; 21(5):1195-202.

16. Wadsworth CT. Frozen shoulder. Phys Ther. 1986;66(12):1878-83.

17. Atchison JW, Tolchin RB, Ross BS et al. Manipulation, traction, and massage. In: Braddom RL, eds, Physical Medicine and Rehabilitation, Elsevier, 2021;316-37.

18. Fryer G. Muscle energy technique: an evidence-informed approach. Int J Osteopath Med. 2011;14(1):3-9.
19. Maitland GD. The slump test: examination and treatment. Aust J Physiother. 1985;31(6):215-9.

20. McKenzie RA, May S. The lumbar spine: mechanical diagnosis and therapy. Waikanae, Spine, 1981;560-3.

21. Stanek J, Sullivan T, Davis S. Comparison of compressive myofascial release and the graston technique for improving ankle-dorsiflexion range of motion. J Athl Train. 2018;53(2):160-7.

22. Chen YW, Wang HH. The effectiveness of acupressure on relieving pain: a systematic review. Pain Manag Nurs. 2014;15(2):539-50.

23. Cohn J. Statistical power analysis for the behavioral sciences. NJ, Lawrence Earlbam Associates, 1988:25-6.

24. Kim CM. Meta-analysis of the effects of various physical therapy method about shoulder adhesive capsulitis: the cases of domestic research. J Kor Phys Ther. 2020;32(5):277-82.

25. Hwang SD. Understanding of meta-analysis. Seoul, Hakjisa, 2014:197-8.

26. Duval S, Tweedie R. Trim and fill: a simple funnel-plot-based method of testing and adjusting for publication bias in meta-analysis. Biometrics. 2000;56(2):455-63.

27. Desjardins-Charbonneau A, Roy JS, Dionne CE et al. The efficacy of manual therapy for rotator cuff tendinopathy: a systematic review and meta-analysis. J Orthop Sports Phys Ther. 2015;45(5):330-50.

28. Ma SY, Je HD, Jeong JH et al. Effects of whole-body cryotherapy in the management of adhesive capsulitis of the shoulder. Arch Phys Med Rehabil. 2013;94(1):9-16.

29. Camarinos J, Marinko L. Effectiveness of manual physical therapy for painful shoulder conditions: a systematic review. J Man Manip Ther. 2009;17(4):206-15.

30. Wilk KE. Current concepts in the rehabilitation of athletic shoulder injuries. In: Wilk KE, eds, The Athlete's Shoulder, New York, Churchill Livingstone, 1994;335-54.

31. Kaltenborn FM, Evjenth O, Morgan D. Manual mobilization of the extremity joints: basic examination and treatment techniques. Olaf Norlis. 1989;1-48.

32. Mulligan BR. Spinal mobilisations with leg movement (further mobilisations with movement). J Man Manip Ther. 1995;3(1):25-7.

33. Yoon JG, Park HJ, Chung BI. Comparison of the mulligan method and electrotherapy in pain reduction and ROM increase in patients with frozen shoulder. PTK. 2000;7(2):66-75.

34. Vicenzino B, Wright A. Effects of a novel manipulative physiotherapy technique on tennis elbow: a single case study. Man Ther. 1995;1(1):305.

35. Wright A. Hypoalgesia post-manipulative therapy: a review of a potential neurophysiological mechanism. Man Ther. 1995;1(1):11-6.

36. Edmon SL. Manipulation and mobilization extremity and spinal techniques. St Louis, Mosby Co, 1993:1-23.

37. Peek AL, Miller C, Heneghan NR. Thoracic manual therapy in the management of non-specific shoulder pain: a systematic review. J Man Manip Ther. 2015;23(4):176-87.

38. Borenstein M, Hedges LV, Higgins JPT et al. Introduction to meta-analysis. NJ, John Wiley \& Sons, 2021:421. 